\title{
Analysis of Luxury Brand and Consumer Psychology
}

\author{
Li Siyao $^{1}$ \\ ${ }^{1}$ International Department of the Affiliated High School of Northeast Normal University Changchun, China, 130,000 \\ Author's Email:3394344025@qq.com
}

\begin{abstract}
Demand for luxury goods increases when a person's wealth or income increases. Society now becomes more and more prosperous than before, and luxury goods can be replaced all the time. Because of this phenomenon, people will realize the trend of this society. According to different people's psychology and company's strategy like expanding new market, this paper analyzes the reasons why more and more people want to buy luxury goods.
\end{abstract}

Keyword: Luxury goods, Set price, People's psychology

\section{INTRODUCTION}

Luxury good is defined as "a kind of consumer goods with unique, or rare characteristics beyond the scope of people's life and needs", also known as non-necessities of life. If their price become so high, people will refuse to buy them. In comparison to life, the higher price means the higher demand for these luxury goods. When people don't get what they want because of restrictions, they pay higher prices for them. Most people cannot understand why people like to use higher and higher prices to buy the non-necessities of life, rather than buying inexpensive ones. The luxury products are inelastic, but in real life they are not, if the price becomes higher, more people want to buy them because these products can also increase their value in the future, and they can show their economic strength.

\section{THE REASON PEOPLE WANT TO BUY HIGH PRICE LUXURY GOODS}

There are four instincts behind human consumption of luxury goods including drive ostentatiousness, camouflage, possession and competition. The main target market of luxury goods is some upper class. Aristocratic people who do not need to worry about their daily life, have sufficient money to enjoy their feeling and using luxury goods to show their status. Although some people think luxury goods can sell at a higher price because of their quality. 'People would like to pay high prices for these products. However, not everyone can afford these luxury goods, they do not have enough personal savings, or a higher salary, but people can even skip meals to buy luxuries that they can't stand, also buying luxury goods can be cost-prohibitive for them. "Consumers under the age of 35 account for $78 \%$ and $74 \%$ of luxury retail sales, accounting for $35 \%$ of global luxury purchases in 2019 . It is worth noting that, according to the data released by the World Luxury Association, the average age of luxury consumers in China has shown a downward trend, dropping from 35 to 25 in the past. Young consumers pay more attention to the pursuit of fashion and personality and have more understanding and attention to luxury brands. In particular, college students born after 1995 are expected to become the main force of luxury market consumption in the next few years. It can be seen that more and more luxury products appear on campus. The young generation of consumers flood into the luxury consumption market and will gradually become the core group of luxury goods."[1] After looking at these data on the research, nearly teenagers in the 18-40 buy luxury goods. This suggests that not only people who have higher income will buy the luxuries, but also the middle class even the person who in the university also try to buy the handbag in Dior. They consume things at prices they cannot afford. Students in the university mean that they do not have income, and they are still children who need their parent's money to live. This situation is not very good for society, during the investigation, most people think luxury goods are sold to younger people that cannot afford them.

The price of luxury goods can be so high one reason is their quantity, another one is people's psychology. "In the inferiority and transcendence" expressed a concept: the more inferiority a person is, the more strongly he will seek for superiority. People who no longer have confidence in themselves in the past seem to have a straighter waist when they go out if they have a famous 
brand on them.[2] People who cannot get respect from others, try to use some decoration to make other think, he is a rich man. If the item is limited and he buys it at a high price, it will give him more confidence. Luxury goods have always been a symbol of status.

Many people believe that only buying expensive products, not the right ones, the more expensive the products are, the more status they will have, so as to satisfy their vanity. This kind of consumer does not care about whether he really needs it or not. What they pay more attention to is the social evaluation of the product. They hope to prove his charm, identity and social status to others through purchasing such luxury goods, and satisfy his vanity from then on[3]. Some people disguise themselves through some luxuries, even though they are not good at making friends. Some people will want to make friends with them through these luxuries. At the same time, this kind of vanity is mainly derived from not confident, because people are afraid if they don't have luxury goods, and lift head with no confidence, and then others will look down on themselves. When inferiority into your body, things will reduce the probability of success. After buying luxury goods, confidence is certainly coming up and people feel that they can hold their head up in front of others, and others will respect them.

The two main motivations for college students to buy luxury goods are to satisfy their vanity and to like the culture and design of a certain brand, accounting for 51.33 percent and 48.67 percent. On the one hand, college students buy luxuries to show off to people around them and highlight their financial resources to satisfy their vanity. On the other hand, consumers will be more inclined to choose the brand in line with their gender and style.[4] Different people have their various interests and style about luxuries through choosing different varieties, and they can better express their fashion and style. For example, Some socialites will better display their status and taste through luxuries.

When college student's consumer groups with unique individuality, pursuing trends and performance desire of self-worth, luxury goods conferred by the unique design and brand culture connotation can help to express selfimage cognition, highlight the personality of the buyer, make it get a strong identity, thus stimulate the purchase desire.[5] Some people will keep buying luxury goods because of their friends' expectations. People will spend nearly $20000 \mathrm{rmb}$ to buy ordinary shoes because it is infinite. During the competition, if people want to gain others' respect, they should win this game by buying the luxury goods as much as they can.

The price of luxury goods can become high. This also attributes to business marketing skills and brands. 150 college students are more inclined to buy luxury goods from Italian brands, accounting for $50 \%$. As one of the cradles of luxury goods and fashion in the world, Italy has given birth to world-renowned luxury brands such as Gucci, Prada, Bvlgari, Valentino, Versace and Fendi. Gucci is deeply loved by college students and ranks second among the most popular brands bought by college students, accounting for $51.67 \%$. $17.33 \%$ of respondents like Bvlgari brand goods, $9 \%$ of college students prefer Prada, and $5.33 \%$ of college students often buy Armani goods. For college students, Italian luxuries focus on design, exquisite production techniques, good quality and relatively low brand premium, which are very attractive to college students.[6]

People will trust this brand for no reason because they are luxurious brands. If there are some problems happened, it must be their problems instead of the products and brands. One possible explanation for this is the human tendency to overemphasize the positive elements of a product and ignore its disadvantages. For example, in the case of Apple Inc. (AAPL), consumers wait overnight for new releases of iPhones, iPads, and Mac computers. Apple products are not technologically unique or superior.[7] Although Apple does not have the most state-of-the-art technology, consumers will still keep buying apple products because of the brand, and they believe the brand will provide products with high quality.

"Pricing mechanism is indispensable to both luxury goods and ordinary goods. Pricing is also important for luxury goods. It not only ensures the quality of luxury goods and satisfies young people's psychology, but also makes them affordable within the limited income range. At the same time, for this group, appropriate price promotion is also desirable, is conducive to attracting the original because of the lack of money and unable to buy people to realize the desire to buy.[8] How to price the luxury goods is really important. If the price is low, some people are shocked because luxury goods are stereotyped to be expensive and a symbol of the rich. However, if the price is too high, they will lose some customers that want to buy but do not have enough budgets. Now Luxury manufacturers should be aware that the main consumer group of luxury goods turn to young people, because they are young, have less original capital accumulation and have low average monthly income, should be relatively soft in pricing. Luxury goods sometimes have a high price because of their scarcity.

If the products only have 500 quantities and they will never sell again, the supply is lower than the demand, the effect of this would occur: the underground market will appear, and the people who want this product will provide a higher and higher price. As a result, other people think this product is worth this price and start to buy the products with this price. This is the strategy used for one cotton doll, this can be luxury goods with the price become higher and higher, but now some dolls are worth $10000 y u a n$ but this cost is same to others, and the original price is 70yuan. It is strange but this phenomenon still exists. This high price is attributed to the shortage and 
scarcity. Some rich people would rather spend a lot of money to satisfy their vanity, to own the hot dolls.

The question in the introduction is that why more and more people are willing to pay a higher price for luxury goods. Luxury goods are also called unnecessary of life, however, nowadays, if the price increase, not like the inelastic one, the quantity will decrease a lot. The price increases a lot, more people try to buy more because they think they are more valuable. On the consumers' aspect, they want others to give them more respect after having the luxury goods, make others think they are rich, show their finical ability, and finish their vanity. After buying luxury goods, people can gain more confidence and show their status, and their taste by choosing different brands to buy expensive products.

\section{THE DEVELOPMENT OF THE LUXURY GOODS INDUSTRY}

On the producers' aspect, know how to build consumers' loyalty and gain more consumer base and how to set the price to the luxury goods.

HERMES was founded in 1837 and is loyal to the traditional handicraft, continuous innovation of the international enterprise with bags, harness, silk products, women's wear, men's wear, gloves, table porcelain and other 16 product categories. Hermes combines traditional craftsmanship with superior raw materials. We all know HERMES is a luxury brand, and HERMES must be the symbol of wealth. According to the diagram, $¥ 63700$ equals \$9802.2621 in American which is also a high price for ordinary residents. "Luxury goods account for $5 \%$ of the world's product sales, but luxury companies don't want to break into the remaining $95 \%$. Beauty may be what they see as a big growth pie -- the global beauty industry is worth about $\$ 532$ billion today, and the market is estimated to be worth nearly $\$ 805$ billion by 2023 ", this is one of the reasons that luxury brand wants to expand their territory.

Nowadays, HERMES tries to enter the cosmetics market by selling the product at lower price which can increase their customer base like young people who cannot spend almost $\$ 10000$ on bags or watches, but selling these daily supplies like cosmetics or perfume. "In 2019, Louis Vuitton and GUCCI branched out into the beauty industry, with the launch of Gucci's beauty line bringing in $\$ 38$ million. By releasing lipsticks, some luxury brands can achieve more than just a modest increase in sales

At the same time, it can also bring the transformation with the active degree, and seek more considerable economic benefits for the brand. Hermes started with the most acceptable lipstick, which is likely to be a test of its full entry into the beauty industry; Hermes, on the other hand, needs to keep pace with its competitors if it wants to stabilize its audience and attract the younger generation."[9] Beauty products can also help luxury brands quickly capture the minds of young consumers, who may not be able to afford a Birkin bag for a while, but can buy Hermes lipstick. They can gratify their own vanity and accept and afford this price of products. The CEO Dumas of HERMES stated that "Obviously, we hope to have the biggest scope possible.

We are trying to do it humbly and cautiously because it's a big market that's already full of strong players, and therefore we have to find our place in it," and they try to branch out into low - and mid-range products. Hermes has put a lot of thought into packaging and price. For the price, they are more expensive than the same kinds of products because they want to set the higher price, which means buying lipsticks in HERMES is also an honor and a wealthy symbol to them. For the package, on the top of the lipstick, HERMES choose Hermes' signature gold book seal pattern, which shows the luxury of the brand.

\section{CONCLUSION}

There are some suggestions for young people. Some advice are provided for younger people to give them correct consumption concepts, avoid impulse consumption, do not blindly compare with the Joneses, to do what we can. College students should have a correct understanding of luxuries. Luxuries are not necessities in life, nor can they completely represent college students' positioning, nor can they measure a person's self-value and success mark, so there is no need to over-pursue luxuries consumption. For the producers, more and more university students become the target market, the different company can lower the price, although they will make lower profits, the social surplus will increase, and the quantity will increase to the equilibrium point. More and more luxury brands try to enter new market like the cosmetics market, to gain more customers and earn more money by using different pricing strategies and different though on the packaging.

\section{ACKNOWLEDGMENT}

I am grateful to Professor for the professional knowledge he gave me, which gave me a better understanding of this major, gave me the idea of writing the paper, and provided me some knowledge that I have never learned before. Then I am grateful to my teaching assistant, my course scheduling teacher and my thesis advisor for helping me set the direction of writing the paper, then the title, and then help me modify the paper. And then thank my parents for giving me the opportunity to participate in this scientific project, and give me extra time to write the paper, and give me some ideas about my paper. 


\section{REFERENCES}

[1]https://www.investopedia.com/articles/personalfinance/091115/psychology-behind-why-peoplebuy-luxury-goods.asp

[2] Chen Rong, Zhou Jue, Liu Yinan, et al. Investigation of College Students' Luxury Consumption Behavior -A Case Study in Shanghai[J]. Modern Business, 2020(32):18-21

[3] In the inferiority and transcendence, Jilin Publishing Group LLC,July 1 2015, by [ AO ] A ER FU LEI DE

[4] Du Siyu. Analysis of Chinese Luxury Consumer Behavior[J]. Superfine, 2021(2):14. DOI:10.12320/j.issn.1673-8756.2021.02.014.

[5] Wang Jiefei. Discussion on luxury marketing strategy based on consumer psychology[J]. Journal of Commercial Economics, 2020(6):70-72.

[6] Chen Rong, Zhou Jue, Liu Yinan, et al. Investigation of College Students' Luxury Consumption Behavior —A Case Study in Shanghai[J]. Modern Business,2020(32):18-21

[7] Chen Rong, Zhou Jue, Liu Yinan, et al. Investigation of College Students' Luxury Consumption Behavior —A Case Study in Shanghai[J]. Modern Business, 2020(32):18-21

[8] By VANESSA PAGE Reviewed by EBONY HOWARD, Article Reviewed on February 13, 2021, Learn about our Financial Review Board, Updated Feb 13, 2021

[9] Hermes sells lipsticks, luxury brands are getting closer and closer to us?[J]. China Glasses ScienceTechnology Magazine,2020(4):80-82. 